\title{
Sonographic Prediction of Ovarian Malignancy in Adnexal Mass
}

\author{
SHAMSUN NAHAR ${ }^{1}$, LATIFA SHAMSUDDIN ${ }^{2}$, MARIAM FARUQUI $^{3}$, GULSHAN ARA $^{4}$
}

\begin{abstract}
:
Objective: To evaluate the role of ultrasound for preoperative diagnosis of ovarian malignancy in adnexal mass.

Materials \& Methods: This prospective observational study was conducted on patients having adnexal mass (n-57) admitted consecutively for surgical exploration in Dept. of OB-GYN of BSMMU from January 2000 - March 2001. Abdominal ultrasonography was performed 10 days preoperatively and 5 sonographic criteria were used to calculate ultrasound score $(0,1 \& 3)$. Definitive diagnosis was based on histo-pathological study . Sensitivity, specificity, positive and negative predictive values of ultrasound score to diagnose ovarian malignancy were detected. Chi square \& student's 't' test were used for statistical analysis.

Results: Sensitivity, specificity, positive and negative predictive values of ultrasound score at cut-off value of 3 were $78 \%, 80 \%, 47 \%$ and $94 \%$ respectively.

Conclusion: For pre-operative diagnosis of ovarian malignancy sonographic scoring system may be introduced easily into the clinical practice where other complementary tests are not available. Combination of serum CA125 and menopausal status into ultrasound score may further improve the diagnostic accuracy in prediction of ovarian malignancy preoperatively.
\end{abstract}

Key words: Ultrasound, adnexal mass.

\section{Introduction:}

Ovarian malignancy is a major cancer killer throughout the globe including Bangladesh. The global incidence is 6.3 per 100,000 and mortality is 3.8 per $100,000^{1}$. The type of operation and experience of the surgeon are important prognostic factors for ovarian malignancy ${ }^{2,3}$. The initial laparotomy is not only important for staging, but also for creation of the best opportunity for maximum de-bulking ${ }^{4}$. But the diagnosis of this adnexal malignancy is difficult due to existence of wide varieties of adnexal pathologies including both the gynaecological and non-gynaecological. The presumptive diagnosis will determine the type of surgery and pre-operative preparation required and may influence the selection of the institution and the seniority and expertise of the surgeon. Sensitive and specific methods for diagnosis of ovarian malignancy are required which would provide a rational basis for referral before diagnostic laparotomy ${ }^{5,6}$.

Sonography quite accurately evaluate the characteristics of adnexal mass (sensitivity 62\%$100 \%)$. However, since the specificity is only $73 \%$ $-95 \%$, it is not possible to predict with certainty the nature of mass ${ }^{7}$. To improve the sonographic diagnostic accuracy many scoring system have been developed for objective evaluation of changes in morphological parameters ${ }^{8-13}$. The application of these scoring system have certainly improved the specificity but not reduced the false positive results . Present study has been conducted to evaluate the accuracy of sonography in diagnosing ovarian malignancy using a scoring system.

1. Associate professor, Dept. of OB-GYN, Central Medical college, Comilla

2. Professor \& Ex-Chairman, Dept. of OB-GYN, Bangabandhu Sheikh Mujib Medical University( BSMMU), Dhaka

3. Senior consultant, Lab Aid Specialized Hospital, Dhaka

4. Associate professor, Dept. of OB-GYN, Sir Salimullah Medical college, Dhaka 


\section{Methods:}

This prospective observational study was conducted during the period of January 2000 - March 2001 in the Department of Obstetrics and Gynecology of Bangabandhu Sheikh Mujib Medical University, Dhaka, with the full co-operation of Department of Pathology \& Department of Radiology \& Imaging of BSMMU, Dhaka . Girls and women admitted consecutively in the Department of Obstetrics and Gynecology for the surgical treatment of adnexal mass fulfilling the selection criteria and having informed willingness in participation into the study ( $n=57$ ) were recruited for the study.

Proper permission to conduct the study was taken from the Chairmen of the concerned departments . Verbal consent from each patient was obtained after informing about the nature and aim of the study . Woman having adnexal mass admitted consecutively for surgical exploration irrespective of age, parity and socio-economic status was the inclusion criteria. Exclusion criteria were woman with adnexal mass unwilling for surgical exploration and women who underwent surgery but histo-pathological report proved as mass of non-adnexal origin. Measurement of outcome variable was ultrasound score. Data was collected in pre-designed data sheet of mixed form and questionnaire type. Socio-demographic characteristics and clinical informations were recorded by interview.

Whole abdomen ultrasound scan was performed by the sonologist of Radiology and Imaging Department using $3.5 \mathrm{MHz}$ transabdominal transducer in full bladder technique within 10 days preoperatively . Ultrasonic features noted were - solidity, multilocularity, bilaterality, ascites and evidence of intra-abdominal metastasis. The resected specimen was sent to the department of pathology preserving in formalin solution immediately after surgery. Histopathological examination was performed by the pathologist and definitive diagnosis was based on it. In one case of ectopic pregnancy, the surgical diagnosis was assumed to be correct.

Ultrasound reports were reviewed without knowledge of final diagnosis and ultrasound score (US) was calculated for each patient as follows: $U S=0$, if none , US $=1$, if 1 and $U S=3$, if $\geq 2$ of the ultrasonic features were present .

Data was analyzed with the help of statistician by SPSS programme of computer. Standard Deviation was taken as a measure of variation and frequency of data was expressed as mean \pm SD. Student's ' $t$ ' test was used to test the differences in distribution of age, parity and ultrasound score among the patients with benign and malignant adnexal mass. Chi-square test was applied in testing differences in distribution of socio-economic status in the same groups . Level of significance was expressed a ' $p$ ' value and values showing $<.05$ was considered as significant to assess the performance of ultrasound score to discriminate malignant from benign adnexal mass. The sensitivity, specificity, positive predictive values (PPV) and negative predictive values (NPV) of ultrasound score were calculated at different cut-off values.

\section{Results:}

Three patients were dropped out due to refusal of surgery in 1 and conversion of surgical treatment into primary chemotherapy in the rest 2 , though 57 patients were initially enrolled for the study. Later on another 5 were excluded where 4 were proved to be non-adnexal malignancy (uterine leiomyosarcoma 2 , fibrosarcoma - 1, and malignant fibrous histocytoma -1) and 1 to be uterine leiomyoma on histopathological examination. Thus, 49 patients comprised the study population . Out of 49 patients , $9(18 \%)$ had ovarian malignancy, where majority ${ }^{3}$ were serous cystadenocarcinoma. On the other hand, 40 (82\%) benign adnexal mass were detected. Majority (9) were functional cyst followed by serous cystadenoma (7) , ovarian endometrioma(6), dermoid cyst (5) and the rest were other benign pelvic conditions.

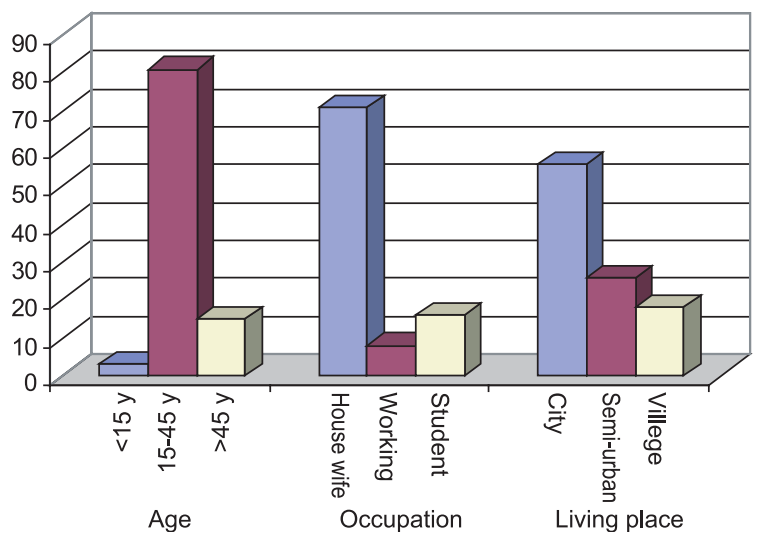

Fig.-1: Distribution of Age, Occupation and Living place in study patients ( $n-49)$ 
Table-I

Distribution of Diagnosis in study patients $(n-49)$

\begin{tabular}{lc}
\hline Diagnosis & No. of patient (\%) \\
\hline A.Benign Adnexal Mass & $40(82 \%)$ \\
Functional cyst & 9 \\
Serous cystadenoma & 7 \\
Mucinous cystadenoma & 2 \\
Dermoid cyst & 5 \\
Parovarian cyst & 3 \\
Ovarian endometrioma & 6 \\
Inflammatory T-O mass & 2 \\
Tubercular pseudocyst & 3 \\
Residual ovarian syndrome & 2 \\
Tubal pregnancy & 2 \\
B. Malignant Adnexal Mass & $9(18 \%)$ \\
Serous cystadeno-Ca & 3 \\
Mucinous cystadeno-Ca & 1 \\
Endometroid adeno-Ca & 1 \\
Granulosa cell tumour & 1 \\
Dysgerminoma & 1 \\
Endodermal sinus tumour & 1 \\
Mixed Germ cell tumour & 1 \\
\hline
\end{tabular}

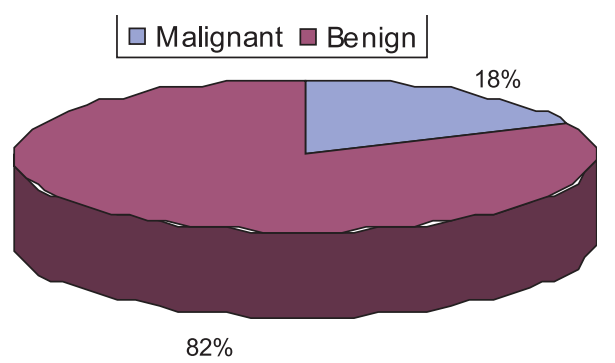

Fig.-2: Distribution of Benign and Malignant Adnexal Mass in Study Patients (n-49)

Table-II

Distribution of Age, Parity, Socio-economic status in study patients (n-49)

\begin{tabular}{|c|c|c|c|c|}
\hline Parameters & $\operatorname{Benign}(n=40)$ & Malignant $(n=9)$ & $\mathrm{P}$ Value & Statistical Tests \\
\hline \multicolumn{5}{|l|}{ Age (years) : } \\
\hline Range & $17-80$ & $11-60$ & $0.950^{N S}$ & UnpairedStudent's \\
\hline Mean \pm SD & $33.42 \pm 12.63$ & $33.11 \pm 16.51$ & & 't' test \\
\hline Median & 30 & 30 & & \\
\hline Parity : & & & & Unpaired \\
\hline Range & 0-10 & $0-9$ & $0.630^{N S}$ & Student's \\
\hline Mean \pm SD & $2.20 \pm 2.49$ & $2.67 \pm 3.12$ & & 't' test \\
\hline Median & 2 & 2 & & \\
\hline \multicolumn{5}{|c|}{ Socio-economic status ${ }^{a}$ : } \\
\hline Poor & $8(20 \%)$ & $2(22 \%)$ & $0.499^{N S}$ & Chi-square \\
\hline Middle & $20(50 \%)$ & $6(67 \%)$ & & test \\
\hline Rich & $12(30 \%)$ & $1911 \%)$ & & \\
\hline
\end{tabular}

a: values were expressed in frequency

NS: not significant 
Table-III

Distribution of Ultrasound Score among study patients ( $n-49)$

\begin{tabular}{lcccc}
\hline Parameters & Benign $(\mathrm{n}=40)$ & Malignant $(\mathrm{n}=9)$ & P Value & Statistical Tests \\
\hline Ultrasound Score: & & & & \\
Range & $0-3$ & $1-3$ & & Unpaired \\
Mean \pm SD & $1.10 \pm 1.131$ & $2.56 \pm .88$ & $.001^{\star * *}$ & Student's \\
Median & 1 & & t'test \\
\hline
\end{tabular}

Table-IV

Sensitivity, Specificity, PPV \& NPV of Ultrasound score

in Prediction of Ovarian Malignancy (n- 49)

\begin{tabular}{lcccc}
\hline Parameters & Sensitivity (\%) & Specificity (\%) & PPV (\%) & NPV (\%) \\
\hline Ultrasound Score: & & & & \\
$\geq 1$ & 100 & 38 & 26 & 100 \\
3 & 78 & 80 & 47 & 94 \\
\hline
\end{tabular}

\section{Discussion:}

Prediction of tissue diagnosis of adnexal mass has remained a challenge for sonographer due to nonspecific sonographic appearances . To improve ultrasonic diagnostic accuracy in ovarian mass, many scoring systems have been developed for objective evaluation of changes in many morphological parameters .This study evaluated the sonographic accuracy in ovarian malignancy diagnosis by utilizing a scoring system .

Both sensitivity and specificity of ultrasound score in present study showed some variation with the previous studies. Present study showed higher sensitivity and lower specificity than three previous studies . In comparison to Jacobs et al. ${ }^{12}$, sensitivity was $78 \%$ vs $71 \%$ and specificity was $80 \%$ vs $83 \%$. Sensitivity $78 \%$ vs $68 \%$ and specificity $80 \%$ vs $82 \%$ were found in comparison to Tingulstad et al ${ }^{9}$. In relation to third research of Morgante et al. ${ }^{10}$ sensitivity and specificity were found $78 \%$ vs $71 \%$ and $80 \%$ vs $87 \%$ respectively. These small variations may be acceptable. On the other hand, in comparison to Davies et al. ${ }^{11}$, specificity was higher ( $80 \%$ vs $74 \%)$, but sensitivity was slightly lower (78\% vs $87 \%$ ) in our population , that was also acceptable. Moreover, like the previous researchers, it was found that along with malignancy, positive ultrasound finding was also associated with benign mass.

\section{Conclusion :}

Present study proved the acceptability of ultrasonographic scoring system in pre-operative prediction of ovarian malignancy. Therefore routine use of this scoring system at places having no facilities for complementary tests like tumour markers, may provide a basis for early referral of patient to higher centre for appropriate surgery by proper surgeon .

Such a scoring system using transvaginal sonography may be a step forward for the prediction of ovarian malignancy.

Moreover , combination of ultrasonography, serum CA 125 and menopausal status in the form of malignancy index may further improve the diagnostic precision in ovarian malignancy .

\section{Reference :}

1. Ferlay J, et al. GLOBOCAN 2008, Cancer Incidence and Mortality Worldwide.

IARC CancerBase No.10; Lyon, France, 2010.

2. Gillis CR, Hole DJ, Still RM, Davis J, kaye SB. Medical Audit, Cancer Registration and Survival in Ovarian Cancer. Lancet 1991; 337: 611-612.

3. Sanfilippo JS and Rock JA. Surgery for Benign Disease of the Ovary. In: Rock JA and Thompson JD(editors). Te Linde's Operative Gynecology. $8^{\text {th }}$ ed . Philadelphia: LippincottRaven Publishers, 1997: pp 625-644. 
4. Shantha V. Malignant Epithelial Ovarian Tumour. In: Ratnam SS, Rao KB and Arulkumaran S (editors) . Obstetrics and Gynaecology. Vol. 1, $2^{\text {nd }}$ ed. Chennai : Orient Longman Ltd. 1999: 395-405.

5. Young RC, Decker DG, Major F, Homesley H and Ellenberg S. Staging Laparoscopy in Early Ovarian Cancer. J Am Med Assoc 1983; 250: 3072-3076 .

6. Pettersson F. Annual Report on the result of treatment in gynecological

cancer . Int J Gynecol Obstet 1990; 36 suppl : 238- 249.

7. Granberg S, Norstrom A, Wikland M. Tumors in the pelvis as imaged by vaginal sonography. Gynecol Oncol 1990;37:224-226.

8. Kurjak A, Pradanijc M. New Scoring System for Prediction of Ovarian Malignancy Based on Transvaginal Color Doppler Sonography . J Ultrasound Med 1992 ; 11: 632-638.

9. Tingulstad S, Hagen B, Skjeldestad FE, Onsrud M, Kiserud T, Halvorsen T , Nustad K. Evaluation of a Risk of Malignancy Index Based on Serum CA125, Ultrasound Findings and Menopausal Status in the preoperative Diagnosis of Pelvic
Masses. Br J Obstet Gynecol 1996; 103:826831.

10. Morgante G, Marca AI, Ditto A, Leo VD . Comparison of Two Malignancy Risk

Indices Based on Serum CA125, Ultrasound Score and Menopausal Status in Diagnosis of Ovarian Masses. Br J Obstet and Gynaecol $1999 ; 106: 524-527$.

11. Davies AP, Jacobs I, Woolas R, Fish A, Oram D. The Adnexal Mass: Bengin or Malignant ? Evaluation of a Risk of malignacy index. $\mathrm{Br} \mathrm{J}$ Obstet Gynaecol 1993; 100:927-931.

12. Jacobs I, Oram D, Fairbanks J , Turner J , Frost C , Grudzinskas JG. A Risk of Malignancy Index incorporating CA125, Ultrasound finding and Menopausal Status for the Accurate Preoperative Diagnosis of Ovarian Cancer. Br. J Obstet Gynaecol 1990 ; 97: 922-929 .

13. Moyle JW, Rochester D, Sider L, Shrock K , Krause $P$. Sonography of Ovarian Tumours : Predictability of tumor type. AJR Am J Roentgenol 1983;141(5): 985-91.

14. Kobayashi M. Use of Diagnostic Ultrasound in Trophoblastic Neoplasm and Ovarian Tumours. Cancer 1976; 38(suppl): 441-452 